\title{
Mechanistic evidence of a Gabriel Colman-type rearrangement
}

\author{
M. Mercedes Blanco, M. Sol Shmidt, and Isabel A. Perillo* \\ Departamento de Química Orgánica, Facultad de Farmacia y Bioquímica, Junín 956 (1113) \\ Buenos Aires. Argentina \\ E-mail: iperillo@ffyb.uba.ar
}

\begin{abstract}
Rearrangement of quinolinimidoacetic acid derivatives induced by alkoxides leading to a mixture of 7-substituted 8-hydroxy-1,6-naphthyridin-5(6H)-ones and 6-substituted 5-hydroxy1,7-naphthyridin-8(7H)-ones (Gabriel Colman-type reaction) was studied. Several chemical evidences accounts for a mechanism in two steps with quinolinamic ester intermediates $(N$ substituted 3-carbamoyl-2-pyridinecarboxylic acid alkyl esters and 2-carbamoyl-3pyridinecarboxylic acid alkyl esters). These compounds were isolated from a reaction in mild conditions and their structure confirmed through an unequivocal synthesis.
\end{abstract}

Keywords: Rearrangement, quinolinimides, naphthyridinones

\section{Introduction}

Rearrangement of $\mathrm{N}$-substituted phthalimides (I, Y: CO; Ar: $\mathrm{C}_{6} \mathrm{H}_{4}, \mathrm{C}_{6} \mathrm{H}_{3} \mathrm{R}$ ) induced by hot alkoxides is a well known method to attain 3-substituted 4-hydroxyisoquinolinones (II, Y: CO; Ar: $\left.\mathrm{C}_{6} \mathrm{H}_{4}, \mathrm{C}_{6} \mathrm{H}_{3} \mathrm{R}\right)$ (Gabriel Colman reaction) ${ }^{1}$ (Scheme 1). Ring expansion requires that the group attached to nitrogen has an enolizable hydrogen. The method is a general one for pentagonal cyclic aromatic imides such as pyridinedicarboximides, namely quinolinimides ${ }^{2}$ and cinchomeronimides ${ }^{3}$, through which properly substituted hydroxynaphthyridinones are obtained.

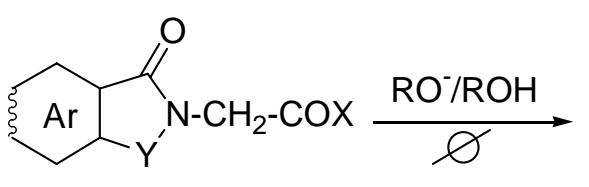

I

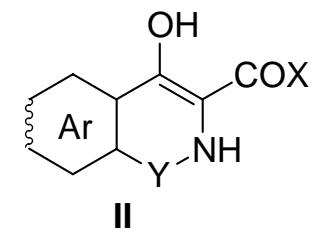

II

\section{Scheme 1}


Extension of the reaction to sulfonimide derivatives (saccharin derivatives) (I, Y: $\mathrm{SO}_{2}, \mathrm{Ar}=$ $\mathrm{C}_{6} \mathrm{H}_{4}, \mathrm{C}_{6} \mathrm{H}_{3} \mathrm{R}, \mathrm{C}_{5} \mathrm{H}_{3} \mathrm{~N}$ ) leads to 4-hydroxy-2H-1,2-benzothiazine-3-carboxylic acid 1,1-dioxide derivatives, thus generating the nucleus of an important NSAD family ("oxicams").

Two reaction mechanisms have been proposed for this type of rearrangement. The first one is a mechanism in two steps which begins with imide alcoholysis leading to an ester intermediate (III). Reaction is completed when a carbanion is formed, which displaces alkoxide anion from the carboalkoxy group formed in the previous step (Dieckmann cyclization). In the second mechanism, alkoxide acts as a base generating a carbanion which in an intramolecular attack to imide carbonyl would lead to an intermediate with a three-membered ring (IV). ${ }^{5}$ Rapid bond rearrangement of this strained cyclic intermediate would yield the final product.

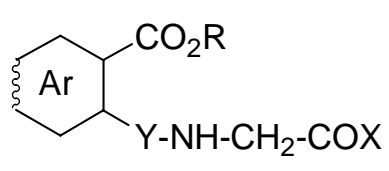

III

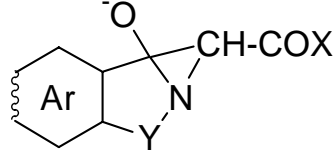

IV

The first mechanism has been confirmed in rearrangement of saccharinacetic acid derivatives, where open intermediary sulfonamides (III, Y: $\mathrm{SO}_{2}$ ) have been isolated working in mild conditions. ${ }^{4 a, d, e}$ In phthalimide series kinetic evidences also support this two step mechanism, ${ }^{6}$ although phthalamic ester intermediates (III, Y: CO) were neither isolated nor even detected in any case.

In our research on compounds having potential biological activity we synthesized a series of hydroxy-1,6- and 1,7-naphthyridinones (2) and (3) through a Gabriel Colman-type rearrangement of $N$-substituted quinolinimide derivatives $\mathbf{1},{ }^{2 \mathrm{~b}, \mathrm{c}}$ an unsymmetrical pentagonal cyclic imide with two carbonyl groups having different reactivity. Our interest in this reaction lead us to go deep into the study of optimal reaction conditions and in the detection and/or isolation of intermediates and by-products. Results threw evidence of the rearrangement mechanism and are presented in this work.<smiles>[X]C(=O)CN1C(=O)c2cccnc2C1=O</smiles>

1<smiles>[X]C(=O)c1[nH]c(=O)c2cccnc2c1O</smiles>

2<smiles>[X]C(=O)c1[nH]c(=O)c2ncccc2c1O</smiles>

3

\section{Results and Discussion}

Rearrangement of compounds 1 only proceeds in the presence of alkoxides. When quinolinimides $\mathbf{1}$ are treated with strong bases different than alkoxides (sodium hydride, calcium hydride, LDA, buthyllithium, DBU) variable quantities of unaltered starting materials together 
with a complex mixture of unidentified products are generally obtained. Compounds having expected hydroxynaphthyridinone features (positive ferric chloride test) were detected in any experiment.

Absence of rearrangement under these conditions is a strong element to discard the second mechanism. This is also supported by the results of reaction of quinolinimidoacetophenone (1, $\left.\mathrm{X}: \mathrm{C}_{6} \mathrm{H}_{5}\right)$ with sodium isopropoxide or tert-butoxide in the corresponding alcohols. Unsatisfactory yields of compounds 2 and $\mathbf{3}$ (Table 1) were obtained and reaction times required for disappearance of starting material are higher than with methoxide or ethoxide, despite the stronger basic character of secondary or tertiary alkoxides than primary ones.

Table 1. Reaction of Compound $1\left(\mathrm{X}: \mathrm{C}_{6} \mathrm{H}_{5}\right)$ with Sodium Alkoxides

\begin{tabular}{ccccc}
\hline \multirow{2}{*}{ Alkoxides } & \multirow{2}{*}{ Time $(\mathrm{min})$} & Temp $\left({ }^{\circ} \mathrm{C}\right)$ & \multicolumn{2}{c}{ Yield $(\%)$} \\
\cline { 4 - 5 } & & & $\mathbf{2}\left(\mathrm{X}: \mathrm{C}_{6} \mathrm{H}_{5}\right)$ & $\mathbf{3}\left(\mathrm{X}: \mathrm{C}_{6} \mathrm{H}_{5}\right)$ \\
\hline Sodium methoxide & 30 & $90-95$ & $45^{2 \mathrm{~b}}$ & $19^{2 \mathrm{~b}}$ \\
Sodium ethoxide & 30 & $90-95$ & 43 & 12 \\
Sodium isopropoxide & $45^{\mathrm{a}}$ & $90-100$ & 22 & traces (TLC) \\
Sodium tert-butoxide & $60^{\mathrm{b}}$ & 120 & traces (TLC) & traces (TLC) \\
\hline
\end{tabular}

${ }^{\text {a }}$ Starting material (40\%) and nicotinic acid (9\%) were also isolated from the crude product of reaction. ${ }^{b}$ A complex mixture of products was obtained. Starting material (15\%) was recovered.

A two step mechanism with quinolinamic ester intermediates 4 and 5 (Scheme 2) is supported by several chemical evidences. Thus, unsatisfactory results obtained in the reaction of quinolinimidoacetophenone $\left(1, \mathrm{X}: \mathrm{C}_{6} \mathrm{H}_{5}\right)$ may be related to the bulky tert-butyl group. This may either influence the alkoxide reactivity in the first step or cause a greater steric hindrance at a carbo-tert-butoxy group than at a carbethoxy group in the second step, as well as the worst nucleofuge characteristics of the tert-butoxide anion.

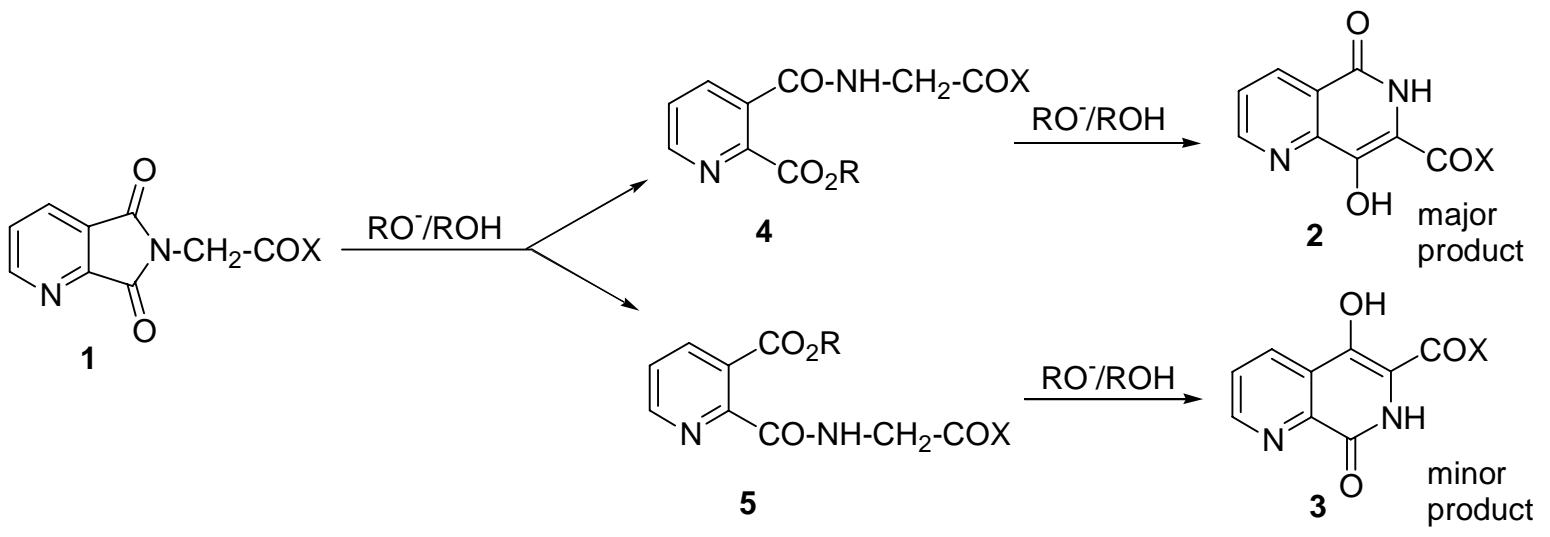

\section{Scheme 2}

Other evidences arise from the nature of reaction products. We have recently reported that $N, N$-disubstituted quinolinimidoacetamide 1 (X: NRR') rearrangements induced by hot 
isopropoxide lead to a mixture of hydroxy-1,6 and 1,7-naphthyridinones (2 and 3, X: NRR') with moderate yields. ${ }^{2 \mathrm{c}}$ Instead, in the case of $\mathrm{N}$-monosubstituted carboxamide derivatives results were hardly satisfactory. The boundary case was represented by the reaction of the $\mathrm{N}$-isopropyl derivative (1, X: $\left.\mathrm{NHCH}\left(\mathrm{CH}_{3}\right)_{2}\right)$ in which the only isolated product was $N-(N-$ isopropylcarbamoyl)methyl-3-pyridinecarboxamide (8). ${ }^{2 \mathrm{c}}$ Carrying out this reaction employing sodium ethoxide, acid (7) and ethyl ether were isolated as other reaction products. Attainment of such products is related to a collateral reaction of intermediary quinolinamic esters which is originated in the acid character of hydrogen amide (Scheme 3).<smiles>[R]NC(=O)CN1C(=O)c2cccnc2C1=O</smiles>

1

$\mathrm{RO} / \mathrm{ROH}$

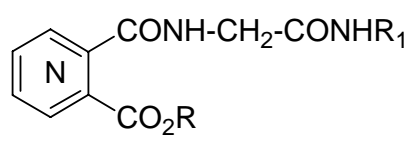

4,5
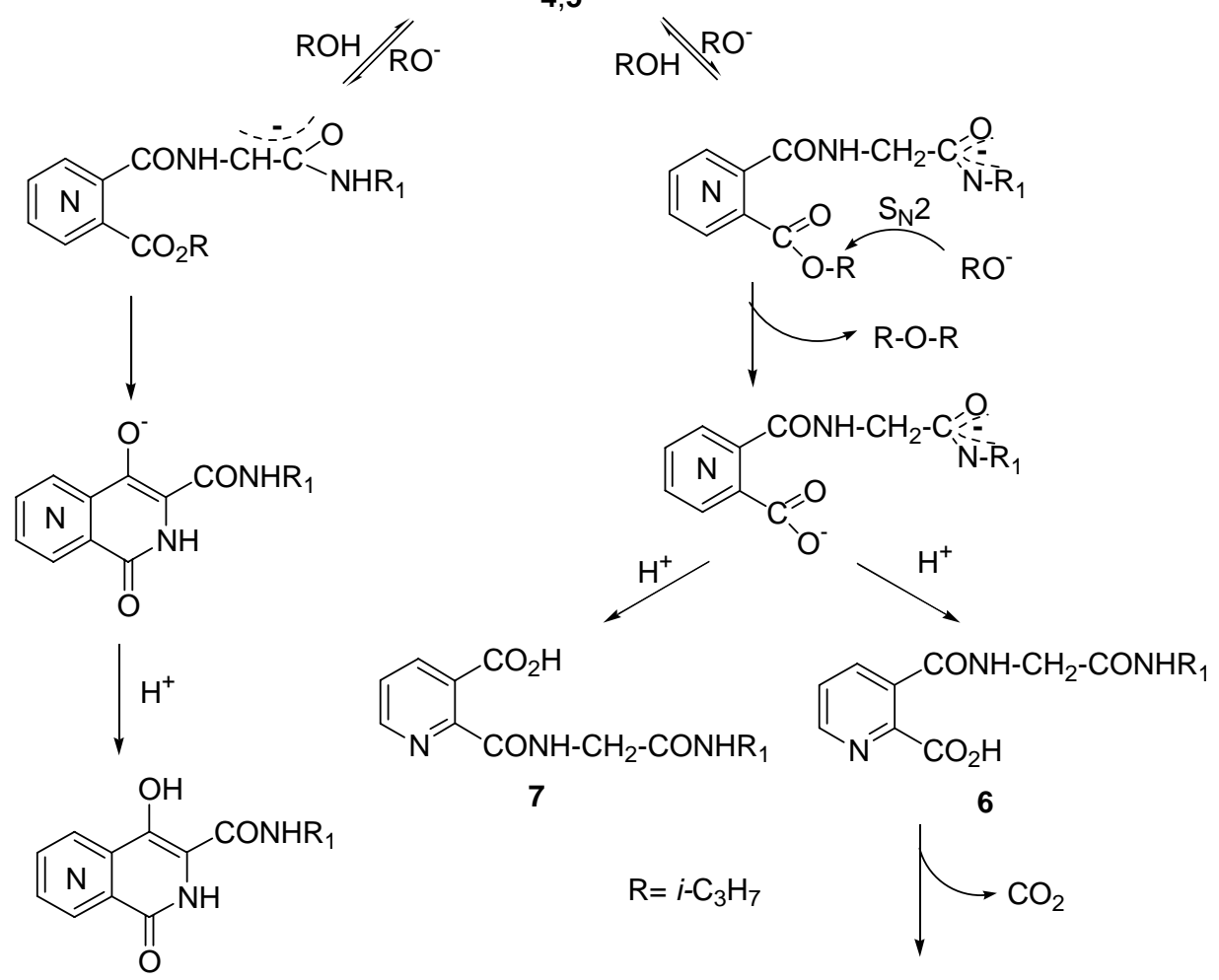

2,3

7<smiles>[R][As]</smiles><smiles>[R1]NC(=O)CNC(=O)c1cccnc1</smiles>

\section{Scheme 3}


Thus, formation of carboxamide anion competes with formation of the enolate carbanion necessary for Dieckmann cyclization, deviating the reaction and leading to the corresponding acids $(6,7)$ through ester cleavage (probably by a $\mathrm{S}_{\mathrm{N}} 2$ mechanism). The easy decarboxylation of 2-pyridinecarboxylic acids explains the attainment of nicotinamide $\mathbf{8}$ as the main product. Ethyl ether formation accounts for the proposed route and discards the possibility of acid attainment as a result of direct imide hydrolysis.

On the other hand, total transesterification reactions observed when alkyl quinolinimidoacetates were treated with alkoxides from primary alcohols other than that of the $\operatorname{ester}^{2 b}$ was justified as a consequence of intermediary quinolinamic ester attainment, as no transesterificated starting compounds were detected and transesterification is only partial when hydroxynaphthyridinones were treated with alkoxides. Reactivity of such intermediates in transesterification reactions is attributed to their character of $\alpha$-substituted ester with an electron withdrawing group and is similar to that of $\alpha$-chloro and $\alpha$-alkoxy esters. ${ }^{7}$

In order to detect the presence, and if it is possible isolate reaction intermediates, the course of methyl quinolinimidoacetate $\left(1, \mathrm{X}: \mathrm{OCH}_{3}\right)$ reaction with sodium methoxide was followed by TLC. Under the vigorous conditions rearrangement is carried out ${ }^{2 b}$ the presence of intermediates was not detected. Working at $0-(-10)^{\circ} \mathrm{C}$ starting material was recovered unaltered. Instead, at $10-$ $15^{\circ} \mathrm{C}$ little amounts of two products having the spectroscopic features of quinolinamic ester intermediates 4 and $5\left(\mathrm{X}: \mathrm{OCH}_{3}, \mathrm{R}: \mathrm{CH}_{3}\right)$ were isolated by chromatography. Their structures were confirmed by unequivocal synthesis starting from methyl quinolinimidoacetate $(\mathbf{1}, \mathrm{X}$ : $\left.\mathrm{OCH}_{3}\right)($ Scheme 4). In the absence of a kinetic study the isolation of compounds $\mathbf{4}$ and 5 in the reaction mixture may only suggest the involvement of the two step mechanism. 


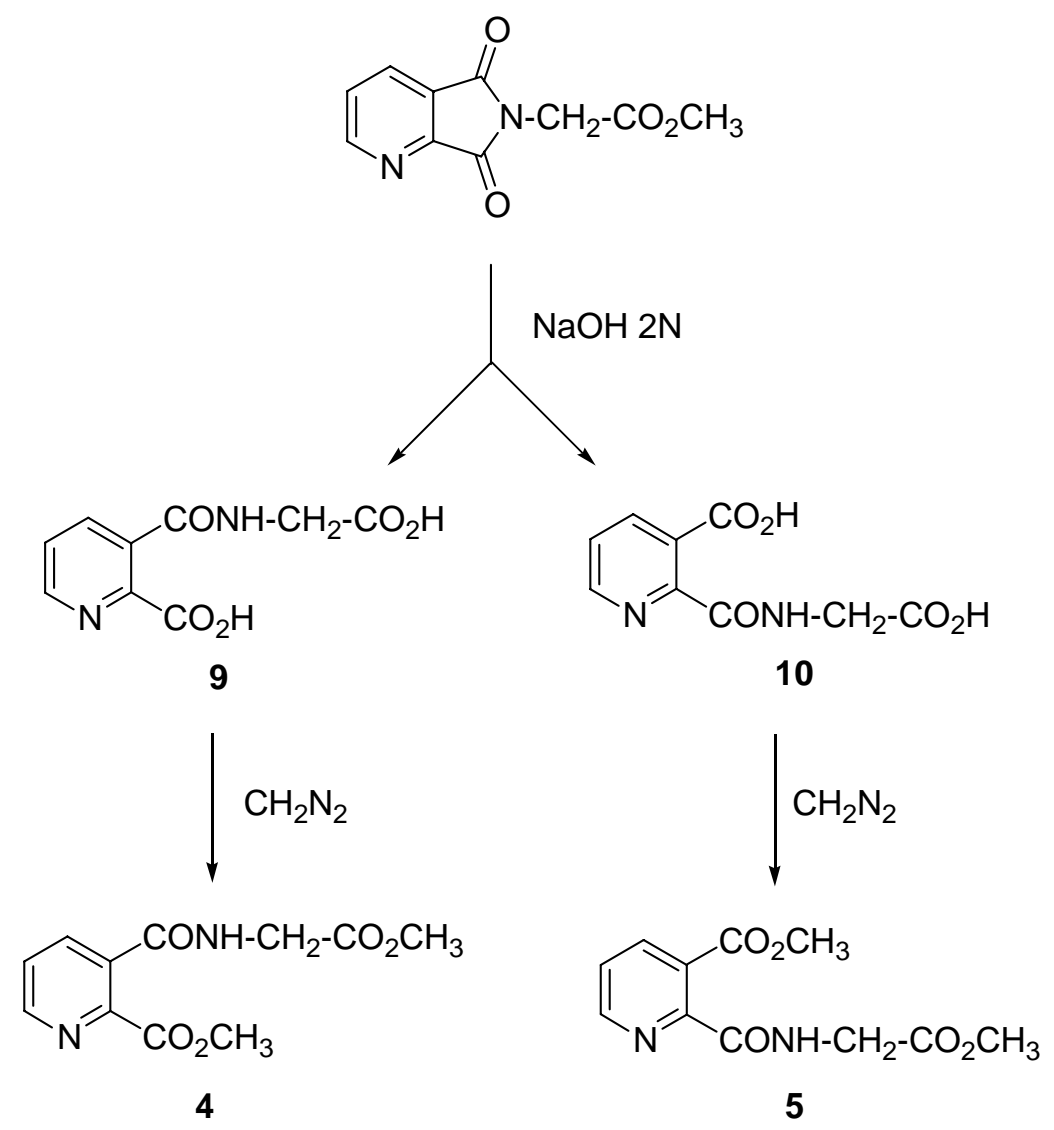

\section{Scheme 4}

In summary, we present in this work a series of chemical evidences indicating that the alkoxide promoted rearrangement of quinolinimidoacetic acid derivatives (1) leading to a mixture of hydroxy-1,6- and 1,7-naphthyridinones $(2,3)$ goes through a two step mechanism with quinolinamic ester intermediates $(4,5)$.

\section{Experimental Section}

General Procedures. Melting points were taken on a Büchi capillary apparatus and are uncorrected. The ${ }^{1} \mathrm{H}$ and ${ }^{13} \mathrm{C}$ nmr spectra were recorded on a Bruker MSL $300 \mathrm{MHz}$. Chemical shifts are quoted in parts per million $(\delta)$ downfield from an internal TMS reference. The presence of exchangeable protons was confirmed by use of deuterium oxide. Proton signals are quoted as: s (singlet), bs (broad signal), d (doublet), dd (doublet of doublet), t (triplet), dt (doublet of triplet), c (quartet) and m (multiplet). MS (electron impact) were performed on a MS Shimadzu QP-1000 instrument at $20 \mathrm{eV}$. HRMS (electron impact) were obtained with a VG AutoSpec device (Micromass Inst) at $20 \mathrm{eV}$. Analytical TLC was carried out on aluminum sheets Silica Gel $60 \mathrm{~F}_{254}$. Preparative thin layer separations (PLC) were carried out by centrifugally accelerated, 
radial chromatography using Chromatotron model 7924T. The rotors were coated with Silica Gel $60 \mathrm{PF}_{254}$ and the layer thickness was $2 \mathrm{~mm}$. Chloroform and increasing percentages of methanol were used as eluent. Reagents, solvents and starting materials were purchased from standard sources and purified according to literature procedures.

\section{Attempts to promote the rearrangement of quinolinimides 1 employing different bases and conditions}

Reactions were carried out employing quinolinimidoacetic acid methyl ester (1, $\left.\mathrm{X}: \mathrm{OCH}_{3}\right)$ (1 $\mathrm{mmol})$ and the base $(4 \mathrm{mmol})$ in the appropriate anhydrous solvent. Reactions were maintained at room temperature for $2 \mathrm{hs}$ and then heated. Samples were taken at different times and poured into ice-acetic acid. Acid solutions were extracted with chloroform, and organic layers were washed, dried with sodium sulfate and analyzed by TLC.

Employing sodium hydride or calcium hydride in DMF, no transformation of starting material was observed after $2 \mathrm{hs}$ at room temperature. Maintaining reaction at the boiling temperature for 5 min a mixture of products was obtained, from which unaltered compound $\mathbf{1}$, quinolinimidoacetic acid $\left(\mathrm{mp} 240^{\circ} \mathrm{C}\right)^{8}$ and nicotinic acid were isolated. Compounds showing chromatographic features of the expected naphthyridines $\mathbf{2}$ and $\mathbf{3}$ were not obtained in any case.

Attempts to promote rearrangement employing DBU in DMF or LDA (prepared from diisopropylamine and buthyllithium in THF) also failed.

\section{Reaction of compound 1 ( $\left.\mathrm{X}: \mathrm{C}_{6} \mathrm{H}_{5}\right)$ with sodium alkoxides. General Procedure}

To a solution of sodium alkoxide prepared from sodium $(0.23 \mathrm{~g}, 0.01 \mathrm{~mol})$ in the corresponding anhydrous alcohol $(5 \mathrm{~mL})$ heated in an oil bath $\left(90-100^{\circ} \mathrm{C}\right)$, $\alpha$-quinolinimidoacetophenone $\mathbf{1}^{2 \mathrm{~b}}$ ( $2.5 \mathrm{mmol})$ were added all at once as the powder. The reaction was maintained in the oil bath while was monitored by TLC. After 30-60 min (depending of the alkoxide) the reaction mixture was poured into ice-acetic acid and extracted with chloroform $(3 \times 10 \mathrm{~mL})$. The organic layers were pooled, washed with water, dried and evaporated in vacuo. The crude products showed two spots which gave positive reaction with ferric chloride. Isolation of hydroxynaphthyridinones 2 $\left(\mathrm{X}: \mathrm{C}_{6} \mathrm{H}_{5}\right)$ and $3\left(\mathrm{X}: \mathrm{C}_{6} \mathrm{H}_{5}\right)$ was achieved by centrifugal PLC. Yields were given in Table 1.

\section{Reaction of compound 1 (X: $\left.\mathrm{NHCH}\left(\mathrm{CH}_{3}\right)_{2}\right)$ with sodium ethoxide}

Compound 1 (X: $\left.\mathrm{NHCH}\left(\mathrm{CH}_{3}\right)_{2}\right)^{2 \mathrm{c}}$ was treated with sodium ethoxide following the procedure described above. After $30 \mathrm{~min}$ reaction was quenched by acidification and $N-(N-$ isopropylcarbamoylmethyl)-3-pyridinecarboxamide (8) crystallized (55\%). After filtering, the acid solution was extracted with chloroform, washed and evaporated in vacuo. From the residue, 2-[N(N-isopropylcarbamoylmetyl)carbamoyl]-3-pyridinecarboxylic acid (7) was isolated as an oil $(15 \%)$ by centrifugal PLC. ${ }^{1} \mathrm{H}-\mathrm{NMR}\left(\mathrm{DMSO}-\mathrm{d}_{6}\right): \delta 11.05(1 \mathrm{H}, \mathrm{bs}, \mathrm{OH}), 8.73(1 \mathrm{H}, \mathrm{dd}, J=4.4$, $1.5 \mathrm{~Hz}, \mathrm{H} 6), 8.15$ (1H, dd, $J=8.2,1.5 \mathrm{~Hz}, \mathrm{H} 4), 7.38(1 \mathrm{H}, \mathrm{dd}, J=8.2,4.4 \mathrm{~Hz}, \mathrm{H} 5), 7.20$ (1H, d, $J=$ $6.1 \mathrm{~Hz}, \mathrm{NH}), 5.95(1 \mathrm{H}, \mathrm{bs}, \mathrm{NH}), 4.35-4.17(1 \mathrm{H}, \mathrm{m}, \mathrm{CH}), 4.13\left(2 \mathrm{H}, \mathrm{d}, J=6.1 \mathrm{~Hz}, \mathrm{CH}_{2}\right), 1.24(6 \mathrm{H}$, d, $J=6.9 \mathrm{~Hz}$ ). HRMS: Calcd. $\mathrm{C}_{12} \mathrm{H}_{15} \mathrm{~N}_{3} \mathrm{O}_{4}$ : 265.106256. Found: 265.106324. 
In another experiment, as soon as the reaction of $\mathbf{1}\left(\mathrm{X}: \mathrm{NHCH}\left(\mathrm{CH}_{3}\right)_{2}\right)$ with sodium ethoxide ended the reflux condenser was replaced by a fractionating column connected to a condenser for downward distillation. The oil bath was heated until distillation began. A liquid $(0.5 \mathrm{~mL})$ was collected which was shown by gas chromatography to be a mixture of ethanol and ethyl ether $(4: 1)$.

Isolation of reaction intermediates 4 and 5 in the rearrangement of compound 1 (X: $\left.\mathrm{OCH}_{3}\right)$ In attempts to detect and isolate reaction intermediates, compound $\mathbf{1}\left(\mathrm{X}: \mathrm{OCH}_{3}\right)^{2 \mathrm{~b}}(2.5 \mathrm{mmol})$ was treated with sodium methoxide $(0.10 \mathrm{~mol})$ varying reaction times and temperatures. Sampling was carried out at suitable time intervals and analyzed by TLC. Under drastic conditions only starting material and naphthyridinones $2\left(\mathrm{X}: \mathrm{OCH}_{3}\right)$ and $3\left(\mathrm{X}: \mathrm{OCH}_{3}\right)$ were detected. Working at $(-10)-0^{\circ} \mathrm{C}$ starting material was recovered. No additional spots were detected in the crude product. By carrying out the reaction at $10-15^{\circ} \mathrm{C}$ and analyzed after $30 \mathrm{~min}$, the crude product showed five spots (TLC, chloroform-methanol 9:1). Separation of compounds by centrifugal PLC afforded compounds 1 (X: $\left.\mathrm{OCH}_{3}\right)$ (Rf: 0.9, main product), and small quantities of compounds $2\left(\mathrm{X}: \mathrm{OCH}_{3}\right)(\mathrm{Rf}: 0.3), 3\left(\mathrm{X}: \mathrm{OCH}_{3}\right)(\mathrm{R} f: 0.4)$ and two other compounds wich were identified as quinolinamic esters $4\left(\mathrm{X}: \mathrm{OCH}_{3}, \mathrm{R}: \mathrm{CH}_{3}\right)(\mathrm{Rf}: 0.8)$ and $5\left(\mathrm{X}: \mathrm{OCH}_{3}, \mathrm{R}\right.$ : $\left.\mathrm{CH}_{3}\right)(\mathrm{Rf}: 0.7)$ by comparison with authentic samples synthesized as follows.

\section{Synthesis of intermediary quinolinamic esters 4 and 5 (X: $\left.\mathbf{O C H}_{3}, \mathbf{R}: \mathrm{CH}_{3}\right)$}

A mixture of of quinolinimidoacetic acid methyl ester $1\left(\mathrm{X}: \mathrm{OCH}_{3}\right)(660 \mathrm{mg}, 3 \mathrm{mmol})$ with $2 \mathrm{~N}$ sodium hydroxide $(3 \mathrm{~mL})$ was warmed on a water bath to $70^{\circ} \mathrm{C}$ during $5 \mathrm{~min}$. The solution was quickly cooled in an ice bath and by slow acidification with acetic acid 3- $(N-$ carboxymethylcarbamoyl)-2-pyridinecarboxylic acid $9(436 \quad \mathrm{mg}, \quad 65 \%)$ and 2-(Ncarboxymethyl)carbamoyl-3-pyridinecarboxylic acid 10 (188 $\mathrm{mg}, 28 \%)$ precipitate as isolated compounds.

Dicarboxylic acid 9 (1 mmol) was dissolved in anhydrous methanol $(3 \mathrm{~mL})$ and an ethereal solution of diazomethane was added in small portions until solution acquires a pale yellow colour. After 24 hours at room temperature reaction mixture was concentrated in vacuo affording compound 4 (X: $\left.\mathrm{OCH}_{3}, \mathrm{R}: \mathrm{CH}_{3}\right)(79 \%)$ which was purified by centrifugal PLC. Similar procedure was employed to obtain compound $5\left(\mathrm{X}: \mathrm{OCH}_{3}, \mathrm{R}: \mathrm{CH}_{3}\right)(82 \%)$ from dicarboxylic acid 10.

3-(N-Carboxymethylcarbamoyl)-2-pyridinecarboxylic acid (9). Mp: $121-122^{\circ} \mathrm{C}$ (methanol) with evolution of gas. ${ }^{1} \mathrm{H}-\mathrm{NMR}$ (DMSO- $\left.d_{6}\right): \delta 12.95(2 \mathrm{H}, \mathrm{bs}, \mathrm{OH}), 8.94(1 \mathrm{H}, \mathrm{t}, J=6.0 \mathrm{~Hz}, \mathrm{NH})$, $8.67(1 \mathrm{H}, \mathrm{dd}, J=4.5,1.5 \mathrm{~Hz}, \mathrm{H} 6), 7.99(1 \mathrm{H}, \mathrm{dd}, J=8.3,1.5 \mathrm{~Hz}, \mathrm{H} 4), 7.60(1 \mathrm{H}, \mathrm{dd}, J=8.3,4.5 \mathrm{~Hz}$, $\mathrm{H} 5), 3.95\left(2 \mathrm{H}, \mathrm{d}, J=6.0 \mathrm{~Hz}, \mathrm{CH}_{2}\right) .{ }^{13} \mathrm{C}-\mathrm{NMR}\left(\mathrm{DMSO}-d_{6}\right): \delta 171.1\left(\mathrm{CO}_{2} \mathrm{H}\right) 167.4$ and 166.4 $\left(\mathrm{CO}_{2} \mathrm{H}\right.$ and $\left.\mathrm{CON}\right), 150.4(\mathrm{C} 6), 150.1(\mathrm{C} 2), 136.0(\mathrm{C} 3), 130.6(\mathrm{C} 4), 124.9(\mathrm{C} 5), 41.2\left(\mathrm{CH}_{2}\right) . \mathrm{MS}$ : $\mathrm{m} / \mathrm{z} 224(40.2 \%)\left(\mathrm{M}^{+}\right), 78$ (100.0\%). Anal. Calcd. $\mathrm{C}_{9} \mathrm{H}_{8} \mathrm{~N}_{2} \mathrm{O}_{5}: \mathrm{C}, 48.22 ; \mathrm{H}, 3.60 ; \mathrm{N}, 12.50$. Found: C, 48.87; H, 3.92; N, 12.04 . 
2-(N-Carboxymethylcarbamoyl)-3-pyridinecarboxylic acid (10). $\mathrm{Mp}$ : $160-161^{\circ} \mathrm{C}$ (methanol). ${ }^{1} \mathrm{H}-\mathrm{NMR}\left(\mathrm{DMSO}-d_{6}\right): \delta 13.00(2 \mathrm{H}, \mathrm{bs}, \mathrm{OH}), 8.95(1 \mathrm{H}, \mathrm{t}, J=5.8 \mathrm{~Hz}, \mathrm{NH}), 8.70(1 \mathrm{H}, \mathrm{dd}, J=4.4$, $1.5 \mathrm{~Hz}, \mathrm{H} 6), 8.00(1 \mathrm{H}, \mathrm{dd}, J=8.0,1.5 \mathrm{~Hz}, \mathrm{H} 4), 7.65(1 \mathrm{H}, \mathrm{dd}, J=8.0,4.4 \mathrm{~Hz}, \mathrm{H} 5), 3.93(2 \mathrm{H}, \mathrm{d}, J=$ $\left.5.8 \mathrm{~Hz}, \mathrm{CH}_{2}\right) .{ }^{13} \mathrm{C}-\mathrm{NMR}\left(\mathrm{DMSO}-d_{6}\right): \delta 171.6\left(\mathrm{CO}_{2} \mathrm{H}\right), 169.3$ and $165.2\left(\mathrm{CO}_{2} \mathrm{H}\right.$ and $\left.\mathrm{CON}\right), 150.2$ (C6), 147.9 (C2), 137.1 (C4), $130.6(\mathrm{C} 3), 126.7(\mathrm{C} 5), 41.4\left(\mathrm{CH}_{2}\right)$. MS: m/z $224(25.4 \%)\left(\mathrm{M}^{+*}\right), 77$ (100.0\%). Anal. Calcd. $\mathrm{C}_{9} \mathrm{H}_{8} \mathrm{~N}_{2} \mathrm{O}_{5}$ : C, 48.22; H, 3.60; N, 12.50. Found: C, 48.61; H, 3.88; N, 12.29 .

3-( $N$-Methoxycarbonylmethylcarbamoyl)-2-pyridinecarboxylic acid methyl ester (4, (X: $\left.\mathbf{O C H}_{3}, \mathbf{R}: \mathbf{C H}_{3}\right)$. It was isolated as an oil. ${ }^{1} \mathrm{H}-\mathrm{NMR}\left(\mathrm{CDCl}_{3}\right): \delta 8.68(1 \mathrm{H}, \mathrm{dd}, J=4.4,1.6 \mathrm{~Hz}, \mathrm{H} 6)$, $8.35(1 \mathrm{H}, \mathrm{bs}, \mathrm{NH}), 7.85(1 \mathrm{H}, \mathrm{dd}, J=7.9,1.6 \mathrm{~Hz}, \mathrm{H} 4), 7.51(1 \mathrm{H}, \mathrm{dd}, J=7.9,4.4 \mathrm{~Hz}, \mathrm{H} 5), 4.27$ (2H, d, $\left.J=5.9 \mathrm{~Hz}, \mathrm{NCH}_{2}\right), 3.95\left(3 \mathrm{H}, \mathrm{s}, \mathrm{OCH}_{3}\right), 3.80\left(3 \mathrm{H}, \mathrm{s}, \mathrm{OCH}_{3}\right) . \mathrm{MS}: m / \mathrm{z} 252(31.2 \%)\left(\mathrm{M}^{+}\right), 105$ (100.0\%). HRMS: Calcd. $\mathrm{C}_{11} \mathrm{H}_{12} \mathrm{~N}_{2} \mathrm{O}_{5}$ : 252.074621. Found: 252.074062.

2-(N-Methoxycarbonylmethylcarbamoyl)-3-pyridinecarboxylic acid methyl ester (5, X: $\left.\mathbf{O C H}_{3}, \mathbf{R}: \mathbf{C H}_{3}\right)$. It was isolated as an oil. ${ }^{1} \mathrm{H}-\mathrm{NMR}\left(\mathrm{CDCl}_{3}\right): \delta 8.59(1 \mathrm{H}, \mathrm{dd}, J=4.5,1.6 \mathrm{~Hz}, \mathrm{H} 6)$, 8.00 (1H, dd, $J=8.0,1.6 \mathrm{~Hz}, \mathrm{H} 4), 7.48$ (1H, dd, $J=8.0,4.5 \mathrm{~Hz}, \mathrm{H} 5), 7.32(1 \mathrm{H}, \mathrm{bs}, \mathrm{NH}), 4.20(2 \mathrm{H}$, d, $\left.J=6.1 \mathrm{~Hz}, \mathrm{NCH}_{2}\right), 3.75\left(6 \mathrm{H}, \mathrm{s}, \mathrm{OCH}_{3}\right) . \mathrm{MS}: \mathrm{m} / \mathrm{z} 252(37.1 \%)\left(\mathrm{M}^{+}\right), 106(100.0 \%)$. HRMS: Calcd. $\mathrm{C}_{11} \mathrm{H}_{12} \mathrm{~N}_{2} \mathrm{O}_{5}$ : 252.074621. Found: 252.074934.

\section{Acknowledgements}

This work was financially supported by the Universidad de Buenos Aires.

\section{References and Footnotes}

1. Gabriel, S.; Colman, J. Ber. 1900, 33, 980, 2630; 1902, 35, 2421. (b) Caswell, L. R.; Campbell, R. D. J. Org. Chem. 1961, 26, 4175. (c) Caswell, L. R.; Atkinson, P. C. J. Heterocyclic Chem. 1966, 3, 328. (d) Caswell, L. R.; Ling-chun Kao, T. J. Heterocyclic Chem. 1966, 3, 333. (e) Caswell, L. R.; Haggard, R. A.; Yung, D. C. J. Heterocyclic Chem. 1968, 5, 865. (f) Schapira, C. B.; Abasolo, M. I., Perillo, I. A. J. Heterocyclic Chem. 1985, 22, 577.

2. (a) Albert, A.; Hampton, A. J. Chem. Soc. 1952, 4985. (b) Blanco, M. M.; Lorenzo, M. G.; Perillo, I. A.; Schapira, C. B. J. Heterocyclic Chem. 1996, 33, 361. (c) Blanco, M. M.; Schapira, C. B.; Levin, G.; Perillo, I. A. J. Heterocyclic Chem. 2005, 42, 493.

3. Gabriel, S.; Colman, J. Ber. 1902, 35, 1358.

4. Among others: (a) Zinnes, H.; Comes, A.; Zuleski, F. A.; Caro, A. N.; Shavel, J. J. Org. Chem. 1965, 30, 2241. (b) Lombardino, J. G.; Wiseman, E. H.; McLamore, W. M. J. Med. Chem. 1971, 14, 1171. (c) Rasmussen, C. R. J. Org. Chem. 1974, 39, 1554. (d) Schapira, C. 
B.; Perillo, I. A.; Lamdan, S. J. Heterocyclic Chem. 1980, 17, 1281. (e) Perillo, I. A.; Schapira, C. B.; Lamdan, S. J. Heterocyclic Chem. 1983, 20, 155.

5. Hauser, R.; Kantor, S. W. J. Am. Chem. Soc. 1951, 73, 1437.

6. Hill, J. H. M. J. Org. Chem. 1965, 30, 620.

7. Janczewski, D.; Synoradzki, L.; Wlostowski, M.; Synlett 2003, 420.

8. Lee, F. C.; Caswell, L. R. J. Heterocyclic Chem. 1971, 8, 831. 